\title{
Routing Protocols in Ad Hoc Networks: A Review
}

\author{
Tanu Preet Singh \\ Dept. of Computer Science \& \\ Engineering \\ Amritsar College of Engineering \& \\ Technology, \\ Punjab, India-143001
}

\author{
Dr. R.K Singh \\ Dept. of Electronics \& Comm. \\ Engineering \\ Uttarakhand Technical University, \\ Dehradun, India
}

\author{
Jayant Vats \\ Dept. of Computer Science \& \\ Engineering \\ Amritsar College of Engineering \& \\ Technology, \\ Punjab, India-143001
}

\begin{abstract}
MANETs is a collection of multi-hop wireless mobile nodes that communicate with each other without centralized control or established infrastructure. It is the network with dynamically and frequently changing topologies as each node (hop) in it is moving. Due to a number of constraints in self-organizing and self-operating networks, routing of it is a challenging problem. To find the optimum routes with minimum control overhead and network resources, there are a lot of routing-protocols namely DSDV, DSR, AODV, TORA, etc. This paper gives a review of existing routing protocols by giving their characteristics, functionality, benefits, limitations and the comparison between them.
\end{abstract}

\section{Keywords}

DSR, DSDV, AODV, TORA.

\section{INTRODUCTION}

Wireless networks are of two types:-

1. Infrastructure or cellular

2. Infrastructure-less or Ad Hoc Wireless Networks. [1]

In Infrastructure wireless networks, the base-stations are stable while communicating nodes are moving. In Infrastructure-less Wireless networks, there is no stable base-station [1] [3] [4]. Mobile nodes move while communicate. Nodes also act as router that provides dynamic topology, thus they form their own network "on the fly". In MANETs, each node acts both as a router and a host and the topology of network also varies rapidly [1] [3] [4] [6] [29]. Some challenges involve in Ad Hoc Networks are:-

1. Power and Bandwidth constraints.

2. Dynamic topologies.

3. Variable capacity links.

4. Energy constrained.

5. Limited physical security.

6. Scalability. [1]

7. Unicast or Multicast Routing.

8. Speed.

9. Frequency of updates or network overheads.

\section{NEED OF ROUTING PROTOCOLS}

To find an efficient route for an un-interrupted communication, many protocols are suggested keeping applications and type of network in view.

\section{BASIC CATEGORIES OF ROUTING PROTOCOLS}

1. on Demand or Reactive Routing Protocols.

2. Table Driven or Proactive Routing protocols.

\subsection{Proactive Protocols}

It maintains information of network independently of need for communication. Update messages are periodically or whenever the topology of network changes [3],[4],[5],[6]. These are derived from legacy Internet Distance Vector and Link state protocols. Thus throughput, bandwidth and power usage might get wasted. In this, each node maintains one or more tables containing routing information to every other node in the network. Examples are:- DSDV, DBF, GSR, WRP, ZRP[1].The advantage of these protocols is that a route to any destination is always available without overhead of route-discovery [1]. The advantage of these protocols is that it cannot work properly when mobility rate in network is high [1].

\subsection{Reactive Routing Protocols}

It discovers routes only when transmission is to be done. It is characterized by path discovery mechanism that is initiated when a source needs to communicate with destination that it does not know how to reach. It saves energy and bandwidths in inactivity. It is suitable for light loads. Examples are:-DSR, AODV, TORA [1] [3] [4] [5] [6] [8].

\section{DSDV (DESTINATION SEQUENCED DISTANCE VECTOR) PROTOCOL}

It is well known table driven protocol, based on Bellman-Ford routing mechanism. The major points in it are:-Freedom from loops in routing table. Some other characteristics are more dynamic and less convergence time [27]. Each node maintains a routing table which contains a list of all possible destination nodes within the network along with the no. of hops required to reach to particular node [27].Each entry of the table marked with a sequence number assigned by the destination node which identifies stale routes, thus avoids formation of loops [1] [6] [7].Every node keep a route table $<$ Destination-address, Metric, Sequence-no. $>$ for every possible destination. It is non-scalable. 


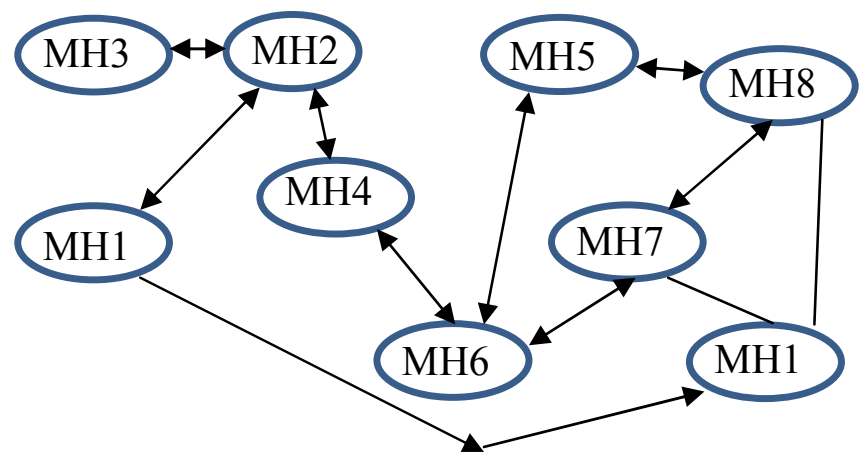

Fig1. Transmission in routing protocol

\begin{tabular}{|l|l|l|}
\hline \multicolumn{1}{|c|}{ Destination } & \multicolumn{1}{|c|}{ Metric } & \multicolumn{1}{c|}{$\begin{array}{c}\text { Sequence } \\
\text { Number }\end{array}$} \\
\hline MH1 & 2 & S406_MH1 \\
\hline MH2 & 1 & S128_MH2 \\
\hline MH3 & 2 & S564_MH3 \\
\hline MH4 & 0 & S710_MH4 \\
\hline MH5 & 2 & S392_MH5 \\
\hline MH6 & 1 & S076_MH6 \\
\hline MH7 & 2 & S128_MH7 \\
\hline MH8 & 3 & S050_MH8 \\
\hline
\end{tabular}

Table1. Entry of node MH1 before movement

\begin{tabular}{|l|l|l|}
\hline \multicolumn{1}{|c|}{ Destination } & \multicolumn{1}{c|}{ Metric } & \multicolumn{1}{c|}{$\begin{array}{c}\text { Sequence } \\
\text { Number }\end{array}$} \\
\hline MH4 & 0 & S820_MH4 \\
\hline MH1 & 3 & S516_MH1 \\
\hline MH2 & 1 & S238_MH2 \\
\hline MH3 & 2 & S674_MH3 \\
\hline MH5 & 2 & S502_MH5 \\
\hline MH6 & 1 & S186_MH6 \\
\hline MH7 & 2 & S238_MH7 \\
\hline MH8 & 3 & S160_MH8 \\
\hline
\end{tabular}

Table2. Entry of node MH1 after Movement

\section{DSR (DYNAMIC SOURCE ROUTING) PROTOCOL}

It is based on the theory of source-based routing. It is sourceinitiated rather than hop-by-hop. This protocol is divided into two essential parts:-

\section{Route Discovery.}

2. Route Maintenance [1].

In this, every node possess route cache to store recently discovered path. When a node desires to start transmission of packets, it first checks its entry in the cache. If it is present there, then it uses that path to transmit and also its source address is attached to packet. If it is not there or entry is expired, then the source broadcasts route request packet to all its neighbors asking for a path to destination [1] [3] [6].

Suppose in e.g. Node $S$ wants to send a packet to node D, but does not know route to $\mathrm{D}$. So, node $\mathrm{S}$ initiates a route discovery. It floods RREQ to its neighbors. Each node appends its own identifier (address) when forwarding RREQ. As the route request packet arrives to any of the node, they checks from their neighbors or their caches about asked destination. If route information is known, they sent back RREP packet to source otherwise they broadcasts RREQ packet to its neighbors. On discovery of route, the data packets are sent from source to destination. Also an entry in the cache is made for future use. Destination $d$ on receiving the first RREP sends route reply. RREP is sent on the route obtained by reversing the RREQ.

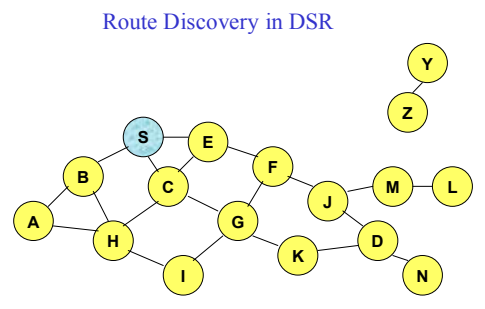

Represents a node that has received RREQ for D from S

Figure 2(a) [30]

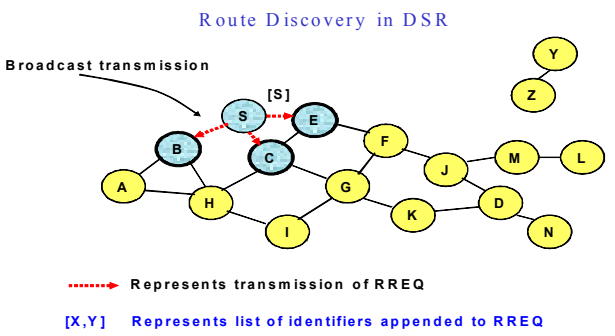

Figure 2(b) [30]

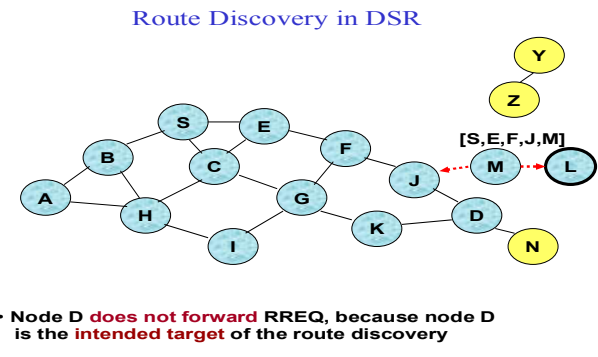

Figure 2(c) [30]

\subsection{Advantages}

1. A route is maintained only between the nodes who want to communicate.

2. Route caching can further reduce route discovery overhead.

3. A single route discovery may yield many routes to destination, due to intermediate nodes replying from local caches.

4. No need to separate routing table as entire route is present in packet header [1]. 


\subsection{Disadvantages}

1. Not scalable to larger networks [1].

2. 2. Requires more processing resources than other protocols [1].

3. Every node requires to spend a lot of time to process control data it receives, even if it is not intended recipient [1].

4. Packet header size grows with length due to source routing.

5. Flood of RREQ packets may reach to every node in the network.

6. Potential collision between RREQ packets sent by different nodes.

7. Stale caches lead to increased overheads [1].

\section{AODV (AD HOC ON DEMAND DISTANCE VECTOR) ROUTING PROTOCOL}

It is variation of DSDV. It is combination of DSR and DSDV. It does not maintain routes from every node to every other node in the network. It minimizes system wide broadcasts to its extreme. Routes in this protocol are discovered when needed and are maintained until they are required. It is forwarded in similar manner as DSR. Large packet headers of small data sometimes degrade performance [1],[3] .AODV attempts to improve on DSR by maintaining routing tables at the communicating nodes. Instead of source routing, it dynamically creates entries in routing tables of intermediate nodes [1],[3],[6]. Whenever a packet is generated for a node for which it has no entry in its table. So, it broadcasts RREQ message to its neighbors [3],[6].they checks their own table. If there is no entry in their routing table, they also broadcasts the packet and also records in its table the address of the node from which it received RREQ. This entry is used in future for establishing the reverse path. These entries are placed in table for a period of time in which RREQ packet propagate through the whole network or produce a route reply packet. RREQ is forwarded until it reaches some node which has a fresh entry for the destination in the routing table or it is reaches to its destination. The final node then sends a route reply packet. The entries in the routing tables of intermediate nodes form the reverse path. Each node that receives the RREP sets a forward pointer to the node from which that packet was received [1]. Thus, the forward path is created from the source to destination on which data packets travel later on. It assumes symmetric (bi- directional) links.

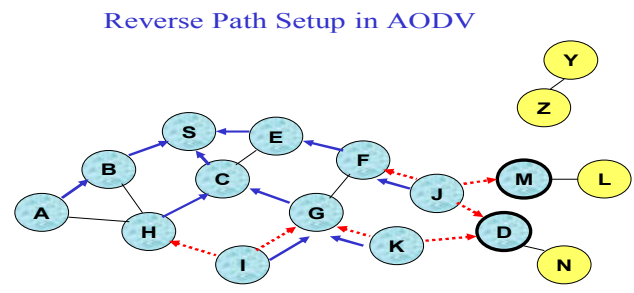

Fig 3(a) [30]

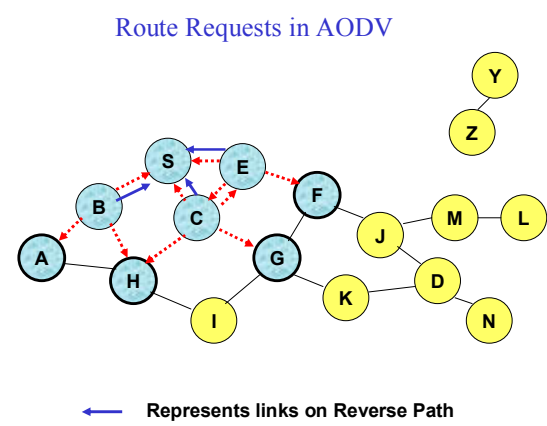

Fig 3(b) [30]

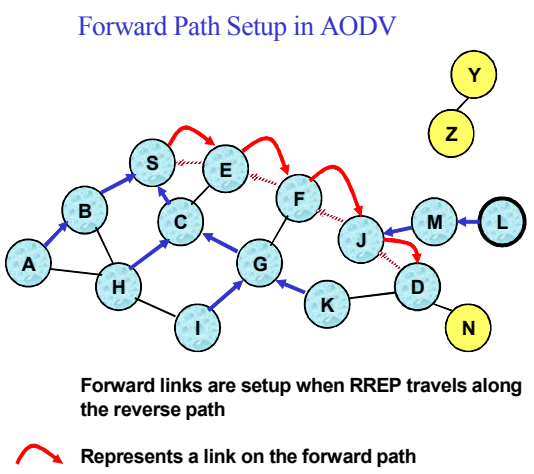

Fig 3(c) [30]

RREQ includes the last known sequence-no for the destination. An intermediate node may also send a route reply [RREP] provided that it knows a more recent path than the one previously known to sender [1]. Intermediate nodes that forward the RREP also record the next hop to destination. A routing table entry maintaining a reverse path is purged after a timeout interval. A routing table entry maintaining a forward path is purged if not used for the active-route -time out interval. 6.1 Link failure of A neighbor of node $\mathrm{X}$ is considered active for a routing table entry if a neighbor sent a packet with a active route time out interval which was forwarded using that entry. Neighboring nodes periodically exchange hello message. When the next hop link in a routing table entry breaks, all active neighbors are informed. Link failures are propagated by means of route error (RRER) messages, which also update destination sequence numbers.

\subsection{Route Error}

When a node $\mathrm{X}$ is unable to forward packet $\mathrm{P}$ on link $(\mathrm{X}, \mathrm{Y})$, it generates RRER. Node $\mathrm{X}$ increments the destination sequence no. for $\mathrm{D}$ cached at node $\mathrm{X}$. The incremented sequence no. is included in RRER. When a source receives RRER, it initiates a new route discovery for $\mathrm{D}$ using destination sequence no at least as large as N. In AODV, routes need not to be included in packet header. Node maintains routing tables containing entries only for active routes. Sequence numbers are used to avoid old and broken links. They also ensure not to form loops. Unused routes are expired even if topology does not change. 


\subsection{Advantages}

1. It favors the least congested route rather than the shortest route.

2. It also supports both Unicast and multicast packet transmission.

3. It also responds very quickly in topological changes that affects the active routes.

4. It does not give extra overhead on data packet [1], [6].

\subsection{Disadvantages}

1. It expects that the nodes in the broadcasts medium can detect each other's' broadcasts.

2. It may be possible that the determination of reasonable expiry time is difficult.

3. As the network size grows, various performance metrics start decreasing.

4. It is vulnerable to a no. of attacks as it assumes each node in its network is cooperatively finding the routes.[1],[6]

\section{TORA (TEMPORALLY ORDERED ROUTING ALGORITHM)}

The theory behind this is that it decouples the generation of potentially far-reaching control message propagation from the rate of topology changes.

The basic steps of this protocol are:-

1. Creating Routes.

2. Maintaining Routes.

3. Erasing Routes.

All the links in a network is represented as the nodes of undirected graph. Each node maintains a "Metric". This metric assigns the direction to links with each neighbor. Routes can be created in Reactive or Proactive mode. The route maintenance is performed only for routers that have a non-null height. Reaction to link failure is initiated only when the node loses its last downstream link. In this protocol, the no. of nodes participating in failure action is minimum. [23]

\section{COMPARISON BETWEEN DIFFERENT ROUTING PROTOCOLS}

For the purpose of comparison simulations are performed on main three routing protocols:-DSDR, DSR, AODV [23]. The simulations are done using ns 2 . The metrics used for comparison are:-

\subsection{Normalized Routing overhead}

It is defined as the number of routing packets transmitted per delivery of a data packet. In it, each hop transmission of routing packet is also counted as one transmission. This gives Scalability of network that is protocol is not scalable if routing overhead increases with the increase in mobility [23].

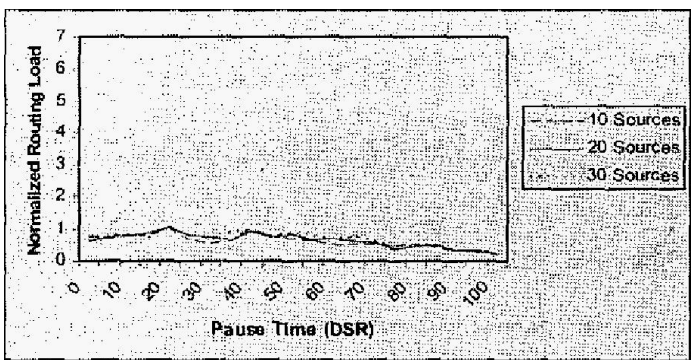

Fig. 4 Normalized Routing load of protocols of 30 sources [23]

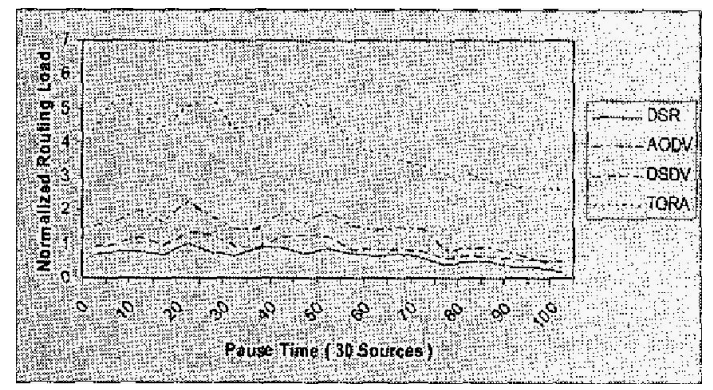

Fig 4.1(a) Normalized Routing Load of DSR with various no of sources [23]

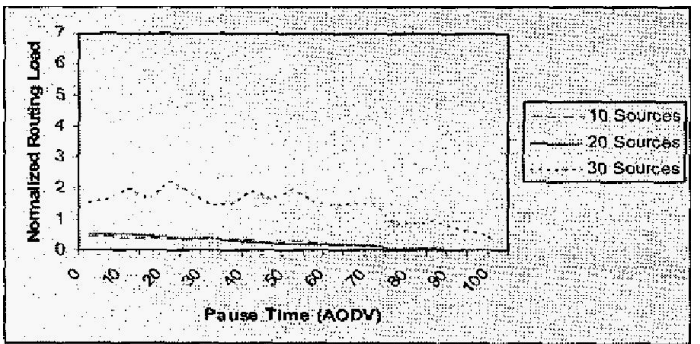

Fig 4.1(b) Normalized Routing Load of AODV with various no. of sources [23]

\subsection{Packet Delivery Fraction}

It is defined as the ratio of data packets received to the packets sent. It tells throughput of the network [23].

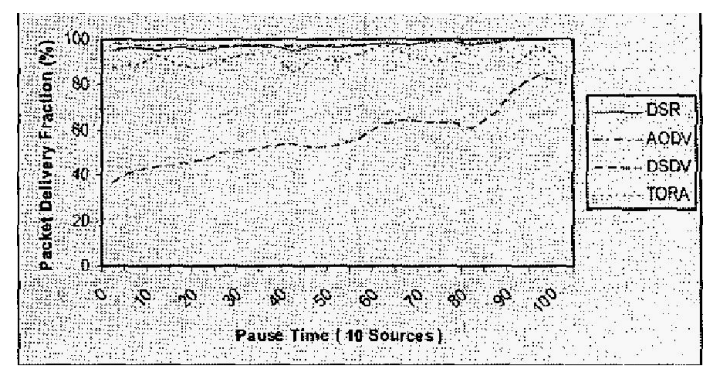

Fig 4.2(a) Packet Delivery Fraction of protocols for 10 sources [23] 


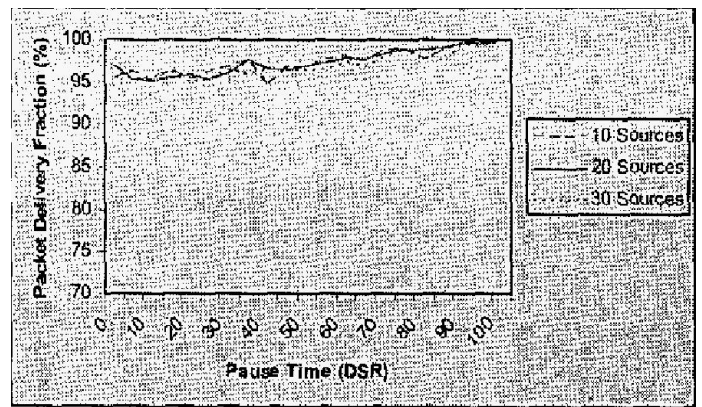

Fig 4.2(b) Packet Delivery fraction of DSDV with various no. of sources [23]

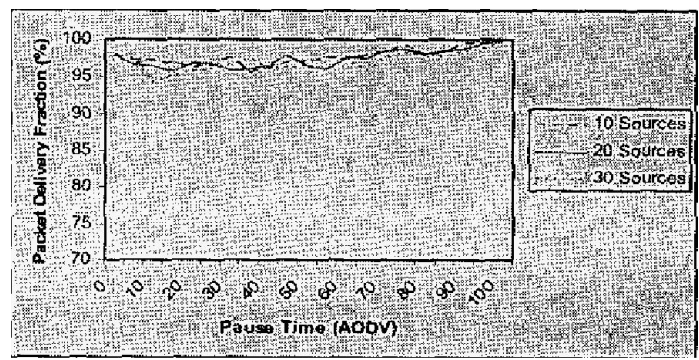

Fig. 4.2(c) Packet Delivery fraction of AODV with various no. of sources [23]

\subsection{Average end-to-end delay}

It is defined as the difference the sending time and the receiving time of the packet [23].

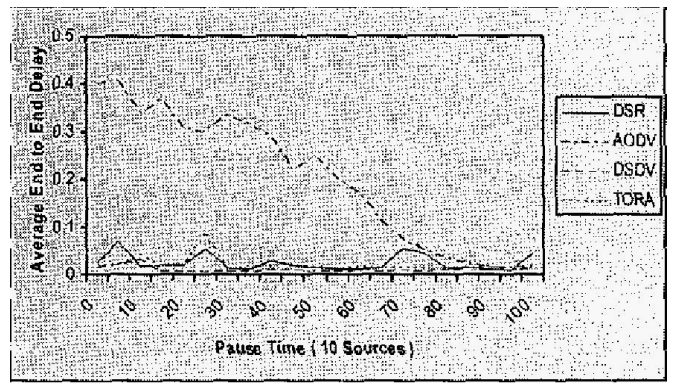

Fig 4.3(a). Average end-to-end delay of protocols with 10 sources. [23]

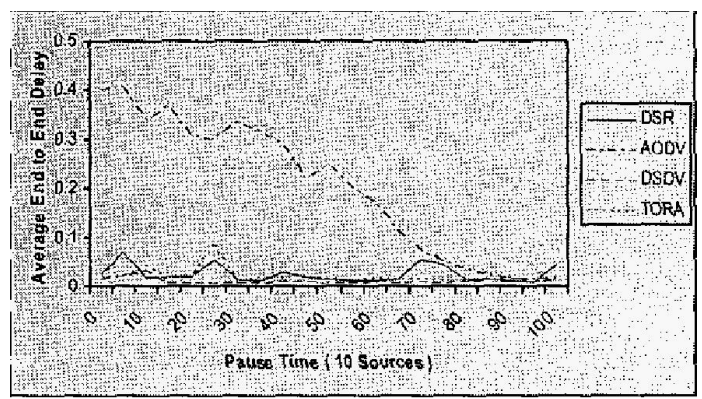

Fig. 4.3(b) Average end-to-end delay of DSR, DSDV, AODV [23]

\section{RESULTS}

1. AODV performs better than DSDV (for 10 nodes) that is normalized routing overhead for AODV is less than DSDV. But as the number of sources increases, it reverses [23].This is because AODV is reactive protocol so as the no. of sources increases; the no. of routing packets also increases.

2. DSR performance is the best as it has the least overheads involved in all the cases [23].

\section{CONCLUSION}

DSR outperforms all other protocols in all scenarios. DSR generates suffers from less routing load than AODV.AODV suffers from end to end delays. DSDV packet delivery fraction is very low for high mobility. DSR lacks if we increase the mobility as then routes will change frequently and cache will have stale routes mostly. If the traffic towards a node increases to an extent such that it gets overloaded then the network reaches to a state of broken link. Also the node can detach from the network due to its low energy. The problem of lowering of threshold energy of mode can be removed by supplying the energy packets to the node or maintaining the record of the remaining energy of the relaying nodes.

\section{REFERENCES}

[1] Sunil Taneja,Ashwani Kush,"A Survey Of Routing Protocols in Mobile Ad Hoc Networks"International Journal Of Innovation, Management and Technology,Vol. 1,No. 3,August 2010 ISSN:2010-0248.

[2] K.Saleem,N.Fisal, S.Hafizah, S.Kamilah, and R.A.Rashid,"A Self-Optimized Multipath Routing Protocol for Wireless Sensor Networks" International Journal Of Recent trends In Engineering, Vol 2, No. 1, November 2009.

[3] Nidhi S. Kulkarni,Balusubramanian Raman And Indra Gupta,"On Demand Routing Protocols For Mobile Ad Hoc Networks-A Review" 2009 IEEE International Advance Computing Conference (IACC 2009)Patiala,India, 6-7 March,2009.

[4] Dr.Shuchita Upadhayaya and charu Gandhi "Quality Of Service Routing In MANETs Using Location And Energy Parameters" International Journal of Wireless and Mobile Networks (IJWMN), Vol 1, No.2, November 2009.

[5] Rekha Patil, Dr. a Damodaram "Cost Based Power Aware Cross Layer Routing Protocol For MANET" IJCSNS International Journal of Computer Science and Network Security, VOL.8 No.12,December 2008.

[6] Arun Kumar B.R., Lokanatha C.Reddy,Prakash S. Hiremath,"Performance Comparision Of Wireless Mobile ad Hoc Network Routing Protocols"IJCSNS International Journal of Computer Science And Network Security Vol. 8,No.6., June 2008.

[7] Mbarushimana, C. and A. Shahrabi: Comparative Study of Reactive and Proactive Routing Protocols Performance in Mobile Ad Hoc Networks, Proc. of The $21^{\text {st }}$ International conference on Advanced Information Networking and Applications Workshops (AINAW’07),pp.679-684,2007. 
[8] Mehran Abolhassan, Tadeusz A. Wysocki, Eryk Dutkiewicz;"A Review of Routing Protocols for MANETs”, Ad Hoc Networks 2(1):1-22(2004).

[9] M.Abolhasan,T.a.Wysocki, \& E.Dutkiewicz, (2004) "a Review of Routing Protocols for Mobile Ad Hoc Networks", Ad Hoc Networks, Vol.2,pp.1-22.

[10] Imrich Chlantac, Macro Conti, Jennifer J.-N. Liu, (2003)"Mobile Ad hoc networking imperatives and challenges" Ad Hoc Networks, Vol 1,pp.13-64.

[11] L.Ouakil,S.senouci , and G. Pujjole, "Performance Comparison of Ad Hoc Routing Protocols Based on Energy Consumption", Ambience Workshop 2002, Torino, Italy, September 2002.

[12] Lie Wang,Lianfang Zhang, Yantai Shu \& Miao Dong (2000), » Multipath source Routing in wireless ad hoc networks»,Proceedings of Canadian Conference on Electrical and Computer Engineering,Vol 1, pp.479-483.

[13] C.E. Perkins, E. M. Belding-Royer , and S. R. Das,"Ad hoc On-Demand Dist ance Vector (AODV) Routing”,Proc. $2^{\text {nd }}$ IEEE Wksp. Mobile Comp. And Apps., Feb. 1999,pp. 90100.

[14] P. Johansson et al.,"Routing Protocols For Mobile Ad Hoc Networks-A Comparative Performance Analysis,"Proc. IEEE/ MOBICOM '99,Aug. 1999 ,pp. 195-206.

[15] E.M. Royer , C-K Toh ,"A Review of Current routing Protocols for Ad Hoc Mobile Wireless Networks".IEEE Personal Communication Magazine,April 1999,pp 46-55.

[16] C.K Toh,'Long-lived ad hoc routing based on the concept of associativity", Internal draft, IETF, March 1999.

[17] J.Broch et al. ," A Performance Comparison onf Ad Hoc Multihop Wireless Networks Routing Protocols," Proc. IEEE/ACM MOBICOM '98,Oct. 1998,pp.85-97.

[18] S. Murthy and J. J Garcia-Luna-Aceves,"An efficient routing protocols for wireless networks", ACM Mobile Networks and Application Journal, Special issue on Routing in Mobile Communication Networks ,1996.
[19] C.E. Perkins \& P. Bhagwat (1994) "Highly Dynamic Destination Sequenced Distance Vector Routing (DSDV) or Mobile Computers",ACM SIGCOMM Conference on Communications Architectures,Protocols and Applications, Vol. 24,pp. 234-244.

[20] David B. Johnson, "Routing Ad Hoc Networks of Mobile Hosts," Proc. IEEE Wksp. Mobile Comp. and Apps., Dec. 1994,pp.158-163.

[21] D.Bertsekas and Gallager, Data Network, pages 404410, second ed. Prentice Hall, Inc., 1992.

[22] Network Simulator-2. www.isi.edu/nsnam/ns/.

[23] Humaira Ehsan and Zartash Afzal Uzmi,"Performance Comparison Of Ad hoc wireless Network Routing Protocols."

[24] David . Johnson and Davis A. Maltz,'DSR in Ad-Hoc Multi Hop Network."

[25] P.Johansson et al.,"Routing Protocols For Mobile Ad Hoc Networks-A Comparative Performance Analysis,"Proc. IEEE/ACM MOBICOM '99,Aug. 1999 ,pp. 195-206.

[26] Natsuru Yamamura,Takuo Nakashima and Seiya Fukushima,"Performance Simulation of Routing Protocols in ad Hoc Wireless Network" The $3^{\text {rd }}$ International Conference on Innovative Computing Information and Control (ICICIC'08).

[27] Khaleel Ur Rahman Khan, A Venugopal Reddy, Rafi U Zaman,K.Aditya Reddy,T Sri harsha,"An Efficient DSDV Routing Protocol for Wireless Mobile Ad Hoc Networks and its Performance Comparison" Second UKSIM European Symposium on Computer Modeling and Simulation.

[28] X.Li, (2006), Ph.D thesis on "Multipath Routing and QoS Provisioning in Mobile Ad Hoc Networks", Queen Mary University of London.

[29] IETF MANET WG (Mobile Ad hoc Network),www.ietf.ora/html.charters/manet charter.html. 